\title{
Alpha rhythm in totally blind children
}

P. M. JEAVONS, G. F. A. HARDing, G. W. FERRIES, AND G. R. S. THOMPSON

University of Aston, Birmingham

In a previous study of 192 blind children, it was found that alpha rhythm was commoner in the electroencephalogram (EEG) of children who had not been blind from birth (Jeavons, I964). In recent years a method has been devised for carrying out statistical analysis of the alpha rhythm using a low frequency analyser and a computer (Bailey and Harding, 1966). The method has been used with success in a number of studies of the EEG (Harding, Jeavons, Jenner, Drummond, Sheridan, and Howells, 1966; Thompson and Harding, r968; Clarke and Harding, 1969), and it was felt that this method should be applied to a further study of the alpha rhythm in blind children. At the same time as the EEG study, the orientation ability and the mobility of the children was studied by an independent observer, so that some of these latter investigations could be related to the EEG study.

\section{Material}

The medical notes of 44 children were studied with a view to obtaining a group of children all of whom were totally blind. Twelve children were excluded because there was some evidence of perception of light. The remaining 32 totally blind children were divided into two groups (Table I):

GROUP I

The onset of total blindness had occurred later than the age of 6 months (14 children)

Table I Causes of blindness in $3^{2}$ children

\begin{tabular}{|c|c|c|c|c|}
\hline \multirow{2}{*}{ Diagnosis } & \multicolumn{2}{|c|}{ Group } & \multicolumn{2}{|c|}{ Total cases } \\
\hline & $I$ & $I I$ & No. & Per cent. \\
\hline Congenital malformation & 2 & 9 & II & 34 \\
\hline Retrolental fibroplasia & 5 & 5 & 10 & $3^{\mathbf{I}}$ \\
\hline Retinoblastoma & 4 & - & 4 & $12 \cdot 5$ \\
\hline Encephalocoele & - & $\mathbf{I}$ & $\mathbf{I}$ & 3 \\
\hline Uveitis, cataract & $\mathbf{I}$ & $\mathbf{I}$ & 2 & 6 \\
\hline Congenital nystagmus & $\mathbf{I}$ & - & $\mathbf{I}$ & 3 \\
\hline Congenital glaucoma & - & $\mathbf{I}$ & $\mathbf{I}$ & 3 \\
\hline Other & $\mathbf{I}$ & I & 2 & 6 \\
\hline Total & 14 & 18 & 32 & \\
\hline
\end{tabular}




\section{GROUP II}

The blindness had been present from birth ( 18 children).

Some details of the age, sex, and intelligence of the patients are given in Table II., 25 children received a formal intelligence test and the mean Intelligence Quotients are very similar (Group I = I08; Group II = 105). Although there were more older children in Group II the age difference is not significant. The sex distribution is different in the two groups, there being a higher proportion of males in Group II.

Table II Age, sex, and intelligence of 32 children

\begin{tabular}{|c|c|c|c|c|}
\hline \multicolumn{2}{|l|}{ Group } & \multirow{3}{*}{$\begin{array}{l}I \\
14 \\
12 \cdot 3 \\
5^{-16}\end{array}$} & \multirow{3}{*}{$\frac{\frac{I I}{18}}{13} \frac{6-16}{6-16}$} & \multirow{3}{*}{$\frac{\frac{\text { Total }}{32}}{\frac{3^{12 \cdot 65}}{5^{-16}}}$} \\
\hline Total cases & & & & \\
\hline Age (yrs) & $\begin{array}{l}\text { Mean } \\
\text { Range }\end{array}$ & & & \\
\hline Intelligence quotient & $\begin{array}{l}\text { Mean } \\
\text { Range }\end{array}$ & $\begin{array}{l}108 \\
92-145 \\
(n=10)\end{array}$ & $\begin{array}{l}105 \\
84-124 \\
(n=15)\end{array}$ & $\begin{array}{l}106 \\
84-145 \\
(n=25)\end{array}$ \\
\hline Sex & $\begin{array}{l}\text { Male } \\
\text { Female }\end{array}$ & $\begin{array}{l}6 \\
8\end{array}$ & $\begin{array}{r}11 \\
7\end{array}$ & $\begin{array}{l}17 \\
15\end{array}$ \\
\hline
\end{tabular}

There was a history of one or more epileptic fits in one member of Group I and three members of Group II.

Because the investigation was concerned with the orientation ability and mobility of the children, an audiometric "sweep frequency" test was carried out; the results (Table III) show that there is no significant difference between the two groups.

Table III Results of sweep frequency test

\begin{tabular}{|c|c|c|c|}
\hline \multirow{2}{*}{ Group } & \multicolumn{3}{|l|}{ Result } \\
\hline & Passed & Failed & Not known \\
\hline $\begin{array}{l}\text { I } \\
\text { II }\end{array}$ & $\begin{array}{r}9 \\
10\end{array}$ & $\begin{array}{l}3 \\
4\end{array}$ & $\begin{array}{l}2 \\
4\end{array}$ \\
\hline
\end{tabular}

\section{Investigations}

\section{E E G}

\section{Methods}

A portable eight-channel EEG machine, modified to provide an output to a two channel FM tape recorder, was taken to Lickey Grange School. Two technicians visited the school and carried out two records on each child, on separate occasions, but usually within a month. Tape recordings were made of the electrical activity (EEG) from the right and left posterior temporal/occipital regions for a period of $2 \frac{1}{2}$ minutes with the eyes open and $2 \frac{1}{2}$ minutes with the eyes closed. The tapes were then taken to the Neuropsychology Unit at the University of Aston and were played back through an EEG machine and analysed. In this way a statistical analysis could be made to reveal any significant differences in the EEG activity.

Independently of the EEG investigation, the children were also studied by one of us (G.W.F.) and assessed as to their ability in orientation and mobility. 
ORIENTATION

\section{Definition}

This study aimed to measure the extent to which a child was aware of his or her spatial location when there were no helpful sounds or other sensations coming from the environment. Orientation was therefore defined in operational terms as the ability to move from one location to another desired location without the aid of external sensory cues.

\section{Method}

The study was based on the method used by Worchel (195I). The child was led over the two equal sides of a right-angled isosceles triangle and was then required to return to the starting point via the hypotenuse.

A playing field within the grounds of Lickey Grange School was used for the study. The ground was considered level enough to give no orientation cues. Although there were trees and buildings around the perimeter, the field was well away from the classrooms and the road running past the school, and the occasional bird calls or the wind were almost the only sounds to be heard in addition to the voices of the investigator and the child taking part in the study. The exception occurred during the testing of two children when a motormower could be heard in another part of the school grounds. The time of the year was spring and the sunshine was bright during part of the test. It is possible that this provided a directional cue which had some small influence on the results.

Three right-angled isosceles triangles of hypotenuse $10 \mathrm{ft}, 16 \mathrm{ft}$, and $22 \mathrm{ft}$ were marked out on the grass near each other by pegging small rubber discs in the ground to mark the corners of the triangles. These discs were very difficult to detect by the children and did not assist them in the test.

The children were taken to the field individually and at the conclusion of the experiment were asked not to discuss the study with anyone who had not already taken part. On arrival at the field the investigator said the following:

"We are going to the middle of one of the open grass spaces and I shall ask you to walk around from one place to another. There will be nothing to bump into.

I am going to guide you in two directions and then stop. I would then like you to walk by yourself to the place where we started, by the straightest path, and stop there. We shall then do the same thing again from the same starting point or a different one. We will do this nine times.

I shall say 'Start!' when we leave the starting point, and 'Go!' when you have to walk by yourself to the start. You say 'Here!' when you think you are back at the starting point."

When the child had been given two practice trials and any misunderstandings had been resolved, nine trials were carried out, three on each triangle, the sequence being a predetermined random order which was the same for all children.

\section{Treatment of data}

The distance to the nearest foot between the starting point and the point where the child shouted "Here!" was measured at each trial and taken to represent the orientation error. Although angular deviation from the hypotenuse path is an integral part of orientation, it had been found to correlate highly with distance from the starting point (Worchel, 1951) and so distance alone was measured. Orientation was represented as the sum of the errors on the nine trials of each child.

32 children were tested on orientation but the results of only 23 were considered as the remainder suffered from additional handicaps or psychological problems which might complicate the relationship between EEG, blindness, and orientation.

The 23 children were ranked according to their orientation score and the EEG or the ten who performed best was compared with that of the ten who performed worst.

The mean and range of orientation error summed over nine trials for the two groups is shown in Table IV (opposite). 
Table IV Mean and range of orientation error summed over nine trials for the best and worst groups

\begin{tabular}{|c|c|c|}
\hline Orientation error $(f t)$ & Mean & Range \\
\hline Best ten & $54^{\circ} \mathrm{O}$ & $16-71$ \\
\hline Worst ten & I 35.7 & $79^{-232}$ \\
\hline
\end{tabular}

MOBILITY

\section{Definition}

The term 'mobility' in this study refers to a blind child's ability to travel without being led, within the boundaries of the school.

\section{Method}

It was considered that mobility would be most adequately determined by obtaining the opinion of teachers who knew the children well. A preliminary questionnaire was drafted and discussed with several members of the teaching staff of the school. As a result of the discussions a final form of the questionnaire was prepared which requested the teacher's opinion of the child on five major distinguishable aspects of mobility and on the overall level of mobility. The teachers were asked to consider the child in relation to the totally blind people they had known and to place him or her in one of two categories if at all possible. The questionnaire used is shown in the Appendix.

Completed questionnaires were obtained for 24 children. Each child was judged independently by three teachers who were well acquainted with him. For comparison with EEG data, children with additional handicaps and psychological problems were excluded, leaving eighteen in the ? results.

\section{Treatment of data}

The eighteen children were divided into ten good travellers and eight poor travellers. This was done by examining the teachers' judgments on Question 6 concerning overall level of mobility. The child was classified as 'good' if all three teachers used Category 2 "Moderate to high mobility", and 'poor' if at least one teacher used Category I "Poor mobility".

Consistency of judgments on Question 6 with judgments on the preceding five questions was used as a check on the division into good and poor. This was done by comparing the number of times the 'good' travellers were placed in Category 1 or Category 2 compared with the 'poor' travellers. Table $\mathrm{V}$ shows the means and ranges.

Table $\mathbf{V}$ Means and ranges of frequency of allocation of 'good' and 'poor' travellers to Category I and Category 2 in Questions I to 5 in the mobility questionnaire

\begin{tabular}{|c|c|c|c|}
\hline \multicolumn{2}{|l|}{ Frequency } & \multirow{2}{*}{$\frac{{ }^{2}}{2 \cdot 6}$} & \multirow{2}{*}{$\frac{\text { Category } 2}{12 \cdot 0}$} \\
\hline 'Good' travellers & Mean & & \\
\hline & Range & $0-4$ & $10-15$ \\
\hline \multirow[t]{2}{*}{ 'Poor' travellers } & Mean & $9 \cdot 4$ & $5 \cdot 1$ \\
\hline & Range & $7-15$ & $0-8$ \\
\hline
\end{tabular}


In the case of a child regarded as good throughout Questions I to 5, Category 2 would be used by the three judges a total of fifteen times and Category I never. If a child was regarded as poor throughout Questions I to 5 by all three judges, Category I would be used a total of fifteen times and Category 2 never.

The children judged 'good' and 'poor' from Question 6 are clearly differentiated by the number of times they are respectively allocated to Categories $I$ and 2 in Questions $I$ to 5 .

Some of these findings were later evaluated in relation to the EEG findings (vide infra).

\section{Results}

Visual interpretation of the EEG records was made without any information about the child other than the age. Artefact was very common. Definite abnormality was present in nine cases and in five more there was a possibility of there being genuine spike abnormality, but artefact made it impossible to be sure. In two of these children there was a history of major epileptic fits. Of those showing definite abnormality, three had spikes or spike-and-wave discharges in their EEG's, only one of them having a history of epilepsy. The other two children suffered from retrolental fibroplasia, a condition known to be associated with EEG abnormality even in the absence of overt epilepsy (Jim and Krause, 1954; Gibbs, Fois, and Gibbs, 1955; Cohen, Boshes, and Snider, 1961; Jeavons, 1964). The EEG's of two children showed sharp waves in the posterior regions - one child had retrolental fibroplasia, the other uveitis. Slow rhythms were present in three cases, but this was a nonspecific abnormality. One child showed unilateral slow waves, without any clinical evidence of localized cerebral abnormality, the cause of blindness being a congenital malformation of the eyes. There was no history of epilepsy and the child had an I.Q. of I I 4 .

The amount of alpha rhythm was assessed for the whole record including the period of hyperventilation and including the portion that was tape-recorded. The assessment was an ordinal scale and comparison of those children who showed little or no alpha rhythm was made with those showing definite alpha rhythm, using the Kolmogorov-Smirnov test. The differences were not found to be significant.

The statistical analyses carried out on the results of frequency analysis were as follows:

(I) Harmonic mean This is a statistical procedure which is used to calculate the mean of data which are in rates - in this case in cycles per second (c/sec.).

(2) Mean abundance This is the arithmetic mean of the abundances of all frequencies.

(3) Kendall's concordance This is a measure of the variability of the ranked analyser abundances from epoch to epoch. The score varies between $\mathrm{o}$ and $\mathrm{I}$, a score of $\mathrm{I}$ indicating no variability.

The computed results of the EEG were then compared in relation to the following factors:

(a) Years of sight;

(b) Orientation ability;

(c) Mobility.

The ten children from Group I who had had some vision for the longest period of time were compared with ten children matched for age from Group II.

Groups I and II were compared with respect to harmonic mean frequency, Kendall's concordance, and mean abundance (Table VI, opposite), using the Fisher-Yates Test of Significance in a $2 \times 2$ contingency table. 
Table VI Comparison of Groups I and II

Group I

It was found that none of the differences between the two groups was significant.

ORIENTATION ABILITY

The ten children who performed best in orientation tests were compared with the ten who performed worst in regards to the computed EEG findings.

None of the EEG factors showed any significant difference between the two groups.

\section{MOBILITY}

Eighteen children were selected and were divided into two distinct groups - good travellers (10) and poor travellers (8). The computed EEG findings in the two groups were compared and none of the differences was found to be significant.

Finally, comparison was made of the relationship of years of sight with orientation and of years of sight with mobility, and no significant relationships were found.

\section{Conclusions}

The hypothesis that the presence of some vision in early life is related to the amount of alpha rhythm seen later in life in the totally blind child is not supported by the present investigation.

The subjects were totally blind children of normal intelligence, and the results can only therefore be compared to those of the Group of 79 children of normal intelligence previously reported (Jeavons, I964), of whom 53 were totally blind.

The similarities and differences between the two populations are shown in Table VII (overleaf). The children are of similar age (mean 12.7 years) but those in the present group are of lower mean intelligence and there is a lower proportion of males. The proportion of patients with congenital malformations is higher in the present survey ( 34 per cent. compared to 9 per cent.) and, while the incidence of retrolental fibroplasia is 
Table VII Particulars of patients with normal intelligence in 1964 and in present survey

\begin{tabular}{|c|c|c|c|}
\hline \multicolumn{2}{|l|}{ Survey } & \multirow{2}{*}{$\begin{array}{l}\text { Present } \\
\frac{32}{5^{6}} \\
44\end{array}$} & \multirow{2}{*}{$\begin{array}{l}1964 \\
53 \\
26 \\
55 \\
45\end{array}$} \\
\hline Blindness & $\begin{array}{l}\text { Total } \\
\text { Partial } \\
\text { From birth (per cent.) } \\
\text { Not from birth (per cent.) }\end{array}$ & & \\
\hline Age (yrs) & $\begin{array}{l}\text { Mean } \\
\text { Range }\end{array}$ & $\begin{array}{l}12 \cdot 8 \\
5^{-16}\end{array}$ & $\begin{array}{l}12 \cdot 7 \\
7-20\end{array}$ \\
\hline \multicolumn{2}{|c|}{ Mean I.Q. } & 106 & I1 6 \\
\hline \multicolumn{2}{|c|}{ Male/female ratio } & I: $\mathbf{I}$ & $2: 1$ \\
\hline \multicolumn{2}{|c|}{$\begin{array}{l}\text { Retrolental fibroplasia (per cent.) } \\
\text { Congenital malformation (per cent.) } \\
\text { Retinoblastoma (per cent.) }\end{array}$} & $\begin{array}{l}31 \\
34 \\
12 \cdot 5\end{array}$ & $\begin{array}{r}32 \\
9 \\
9\end{array}$ \\
\hline Total case & & $3^{2}$ & 79 \\
\hline
\end{tabular}

similar, there are other differences in incidence of other aetiological factors. It is impossible to say whether the above differences account for the difference in the findings related to the alpha rhythm.

All the patients in the previous investigation had their EEG's taken in a hospital EEG department, whereas the EEG's in the present study were taken in the familiar surroundings of the children's own school. Since the amount of alpha rhythm in the blind person is undoubtedly dependent on the relaxation of the individual, this fact may have some influence on the findings.

There is no evidence that the ability of the totally blind child to orientate well is related to the alpha rhythm, nor is there any difference in the alpha rhythm findings in relation to the child's mobility rating.

From this investigation we conclude that routine electroencephalography with frequency analysis and computation is not likely to provide information which would be useful in the training or education of blind children. Of course the EEG is useful from the medical point of view, and in this study nine of the 32 children showed definite abnormality in their EEG records.

Our interest in visual deficit has continued, and for some time we have been studying the use of the EEG in the diagnosis of total blindness or hemianopia in children who are unable to communicate because of age or because of brain damage. The technique, which uses a Computer of Average Transients, appears to be the only accurate method of diagnosing total blindness in the non-communicating infant and we think that it is in this field that the electroencephalographer is most likely to benefit the blind child.

We are grateful to the Birmingham Royal Institution for the Blind for providing a grant tcwards this research, and to all the staff at Lickey Grange School, especially the Principal, Mr. D. W. F. Folley, for their help.

The investigation depended on the co-operation of the children and the skill of the technicians Miss $\mathbf{E}$. Furness, Miss J. Bruce, and Mrs. C. Jones. 


\section{References}

bailey, P. E., and harding, G. F. A. (1966) Proc. electro-physiol. Technol. Ass., 13, 4 I ClARKE, L. G., and HARDING, G. F. A. (1969) Ibid., r6, 94 COHEN, J., Boshes, L. D., and SNider, R. S. (I96I) Electroenceph. clin. Neurophysiol., 13, 9I 4 GIBBS, E. L., FOIS, A., and GIBBS, F. A. (1955) New Engl. 7. Med., 253, I IO2

HARDiNG, G., JEAVONS, P. M., JENNER, F. A., DRUMMOND, P., SHERIDAN, M., and hoWells, G. W. (I966)

Electroenceph. clin. Neurophysiol., 21, 59 JEAvons, P. M. (1964) Brit. 7. Ophthal., 48, 83

Jim, v. K. s., and Krause, A. c. (1954) Amer. 7. Ophthal., 38, 337

THOMPSON, C., and HARDING, G. F. A. (I968) Electroenceph. clin. Neurophysiol., 25, 509

worchel, P. (195I) “Space Perception and Orientation in the Blind" Psychological Monographs, 65,

No. I 5

\section{Appendix}

\section{MOBILITY QUESTIONNAIRE}

(1) What is the traveller's rate of movement?
(1) Slow.
(2) Moderate to rapid.

(2) What is the traveller's degree of veer from intended direction in favourable travelling conditions? (Please ignore behaviour in large open spaces or loud noise.)
(I) Large.
(2) Small.

(3) Does the traveller almost always maintain orientation while moving about?
(I) No.
(2) Yes.

(4) Does the traveller seem to achieve object detection by hearing (possibly assisted by sound-producing techniques such as tapping or whistling), smell, and sensing of temperature changes?
(I) A little.
(2) Considerably.

(5) To what extent is the traveller hesitant while moving in favourable travelling conditions?

(Please ignore behaviour in large open spaces or loud noise.)

(I) Very hesitant. (2) Modera ely to slightly hesitant.

(6) What do you think is the traveller's overall level of mobility in favourable conditions, within the boundaries of the school, when mobility is defined in terms of ability to travel speedily, accurately, safely, and confidently with a minimum of sighted help?
(1) Poor mobility.
(2) Moderate to high mobility. 